\section{Emergence of Grass Seedlings Under Crop Residue Culture ${ }^{1}$}

\section{JAMES R. STROH AND VERNON P. SUNDBERG}

Manager and Agronomist, Plant Materials Center, Soil Conservation Service, U.S. Department of Agriculture, Bridger, Montana.

\section{Highlight}

Five grass species were fall seeded on dryland under three cultural treatments-summer fallow, tilled stubble, and standing stubble-in 1966, 1967, and 1968. Seedling emergence was recorded the following spring on each of the seedbeds. Significant differences in emergence were found among the grasses and the seedbeds with the summer fallow treatment generally producing more seedlings. For practical purposes of stand establishment and area occupancy, however, all cultural treatments produced adequate stands. Interactions among years, seedbeds, and grass species were too great to permit predictions of consistency for any one cultural treatment. Dramatic sup-

\footnotetext{
${ }^{1}$ Received May 27, 1970; accepted for publication September $17,1970$.
}

pression of rhizome extension of western wheatgrass occurred under the crop residue treatments. This suppression was too severe to be attributed entirely to nitrogen deficiency. Phytotoxicity of the plant residue is suspected as a contributing factor.

Seeding grasses on abandoned cropland, or land converted from cash crops into permanent pasture, is a common practice in submarginal dryland areas of the Great Plains. Cultural methods and seedbed preparation techniques are well established with summer fallow, tilled grain stubble, and standing grain stubble the three most recommended and used (Anderson et al., 1957; Barnes et al., 1952; Clark and Heinrichs, 1941; Douglas et al., 1960; Launchbaugh, 1966; Parker, 1961; Sittler, 1958; Stark et al., 1946; Staten, 1943). Their primary purpose is the conservation of soil moisture for germination and growth of the seedlings. The added advantage of wind or water erosion control is achieved with the tilled stubble and standing stubble techniques.

Successful establishment of grasses on difficult sites varies widely in spite of the application of 
Table 1. Numbers of seedlings emerging from five grasses seeded at a rate of 10 PLS per row foot across three cultural treatments. Seeded October 1966, emergence recorded June 1967. Averages of three replications. October through June precipitation was 10.09 inches.

\begin{tabular}{|c|c|c|c|c|}
\hline \multirow[b]{2}{*}{ Grass species } & \multicolumn{3}{|c|}{ Cultural treatments } & \multirow[b]{2}{*}{ Average } \\
\hline & $\begin{array}{l}\text { Summer } \\
\text { fallow }\end{array}$ & $\begin{array}{l}\text { Tillcd } \\
\text { stubble }\end{array}$ & $\begin{array}{l}\text { Standing } \\
\text { stubble }\end{array}$ & \\
\hline Green needlegrass & 11.4 & 8.9 & 8.3 & $9.5 \mathrm{a}^{*}$ \\
\hline Western wheatgrass & 6.1 & 4.3 & 3.8 & $4.7 \mathrm{~b}$ \\
\hline Switchgrass & 4.5 & 4.4 & 3.9 & $4.3 \mathrm{~b}$ \\
\hline Thickspike wheatgrass & 4.8 & 5.3 & 4.4 & $4.8 \mathrm{~b}$ \\
\hline Prairie sandreed & 2.4 & 1.3 & 1.7 & $1.8 \mathrm{c}$ \\
\hline \multirow[t]{2}{*}{ Average } & 5.8 & 4.8 & 4.4 & 5.0 \\
\hline & $x^{*}$ & $\mathrm{y}$ & $\mathrm{y}$ & \\
\hline
\end{tabular}

* Duncan's Multiple Range Test $@ \mathbf{P}=.01$, values with the same letters following are not significantly different.

these cultural methods. Failures are most often attributed to adverse weather conditions even though these methods supposedly reduce the effects of weather (Launchbaugh, 1966). Occasionally a study of cultural methods shows an adverse effect of seeding in small grain stubble. Douglas et al. (1960) found that seeding grasses into wheat stubble produced good stands but plant devclopment was retarded. Five years were required for the grass to reach full production, as compared to three years for seedings on fallowed land.

The purpose of this study was to evaluate emergence of range grasses under summer fallow, tilled stubble, and standing stubble cultural methods under the very dry conditions of southern Montana, and to determine the most consistently successful method over a period of years.

\section{Methods and Materials}

The three cultural methods of summer fallow, tilled stubble, and standing stubble were applied on a Heldt silty clay loam soil at Bridger, Montana, during 1966, 1967, and 1968. This was a dryland site with a 50-year mean annual precipitation of 10.35 inches. Each of the study areas had been sown to spring wheat the year prior to treatment. In the treatment year each study area was spring plowed and one-third of the area summer fallowed throughout the season as needed to prevent weed growth. Two-thirds were replanted to spring wheat and mowed to an 8-inch stubble height at the post-bloom stage with the cut material left on the site. One-half of the wheat area was then incorporated into the surface 4 inches of soil and the other half left standing. These three treatments were repeated on separate areas for each of the three years indicated.

In October of each year that the cultural treatments were established, five grass species were seeded across the three seedbeds: thickspike wheatgrass (Agropyron dasystachyum), western wheatgrass (A. smithii), prairie sandreed (Calamovilfa longifolia), switchgrass (Panicum virgatum), and green needlegrass (Stipa viridula). The grasses were seeded
Table 2. Numbers of seedlings emerging from five grasses seeded at a rate of 10 PLS per row foot across three cultural treatments. Seeded October 1967, emergence recorded June 1968. Averages of three replications. October through June precipitation was 12.20 inches.

\begin{tabular}{lrrrr}
\hline \hline & \multicolumn{3}{c}{ Cultural trcatments } & \\
\cline { 2 - 4 } \multicolumn{1}{c}{ Grass species } & $\begin{array}{c}\text { Summer } \\
\text { fallow }\end{array}$ & $\begin{array}{c}\text { Tilled } \\
\text { stubble }\end{array}$ & $\begin{array}{c}\text { Standing } \\
\text { stubble }\end{array}$ & Average \\
\hline Green needlegrass & 10.5 & 9.2 & 16.2 & $12.0 \mathrm{a}^{*}$ \\
Western wheatgrass & 6.5 & 3.9 & 5.0 & $5.1 \mathrm{~b}$ \\
Switchgrass & 6.4 & 4.0 & 7.8 & $6.1 \mathrm{~b}$ \\
Thickspike wheatgrass & 3.4 & 2.8 & 2.9 & $3.0 \mathrm{c}$ \\
Prairie sandreed & 0.3 & 0.2 & 0.3 & $0.3 \mathrm{~d}$ \\
Avcragc & 5.4 & 4.0 & 6.4 & 5.3 \\
& $\mathrm{x}$ & $\mathrm{y}$ & $\mathrm{x}$ & \\
\hline
\end{tabular}

* Duncan's Multiple Range Test @ $\mathrm{P}=.01$, values with the same letters following are not significantly different.

with a grain drill at a calibrated rate of 10 pure live seed (PLS) per foot of row in 7-inch row spacings. The seeding rates were calibrated on the basis of laboratory germination tests. The experimental design used for each planting was randomized split-block with three replications using the grass species as main blocks and the cultural treatments as split blocks. The split-block was 8 by 70 feet. No fertilizer was used in this study.

In late June following each fall planting the number of seedlings emerged per row foot were counted. Ten 3-foot samples from each split-block were taken, averaged, and reduced to the number of seedlings per row foot. The 1966 and 1968 plantings were plowed in the fall of the same year the seedlings emerged. The 1967 planting was allowed to grow through the second (1969) season.

\section{Results and Discussion}

The cultural treatments showed highly significant differences in the numbers of seedlings emerging per row foot each year (Tables 1, 2, and 3).

Table 3. Numbers of seedlings emerging from five grasses seeded at a rate of 10 PLS per row foot across three cultural treatments. Seeded October 1968, emergence recorded June 1969. Averages of three replications. October through June precipitation was 11.25 inches.

\begin{tabular}{lcccc}
\hline \hline & \multicolumn{3}{c}{ Cultural treatments } & \\
\cline { 2 - 4 } \multicolumn{1}{c}{ Grass species } & $\begin{array}{c}\text { Summer } \\
\text { fallow }\end{array}$ & $\begin{array}{c}\text { Tilled } \\
\text { stubble }\end{array}$ & $\begin{array}{c}\text { Standing } \\
\text { stubble }\end{array}$ & Average \\
\hline Green needlegrass & 12.0 & 9.6 & 6.8 & $9.5 \mathrm{a}^{*}$ \\
Western wheatgrass & 2.5 & 1.8 & 1.3 & $1.9 \mathrm{~b}$ \\
Switchgrass & 0.8 & 0.8 & 0.5 & $0.7 \mathrm{~cd}$ \\
Thickspike wheatgrass & 2.5 & 1.6 & 0.8 & $1.6 \mathrm{bc}$ \\
Prairie sandreed & 0.9 & 0.4 & 0.5 & $0.6 \mathrm{~d}$ \\
Average & 3.7 & 2.8 & 2.0 & 2.9 \\
& $\mathrm{x}$ & $\mathrm{y}$ & $\mathrm{z}$ & \\
\hline
\end{tabular}

* Duncan's Multiple Range Test @ P $=.01$, values with the same letters following are not significantly different. 
Table 4. October through June monthly precipitation (inches) at Bridger, Montana. ${ }^{1}$

\begin{tabular}{lrrr}
\hline \multirow{2}{*}{ Month } & \multicolumn{3}{c}{ Precipitation in inches } \\
\cline { 2 - 4 } & $1966-67$ & $1967-68$ & $1968-69$ \\
\hline October & .89 & 1.05 & .33 \\
Novembcr & .52 & .91 & .48 \\
December & .84 & 1.72 & .57 \\
January & .86 & 1.61 & 1.27 \\
February & .66 & .23 & .03 \\
March & .55 & .61 & .57 \\
April & 1.55 & .51 & .96 \\
May & .79 & 1.74 & 1.54 \\
June & 3.43 & 3.82 & 5.50 \\
Total & 10.09 & 12.20 & 11.25 \\
\hline
\end{tabular}

${ }^{1}$ From precipitation records maintained at the SCS Plant Materials Center, Bridger, Montana.

The summer fallow treatment was highest in seedling emergence two of the three years. The standing stubble treatment was lowest in seedling emergence two of the three years. The average planting emergence and the individual treatment emergences within each planting were not related to October through June precipitation. Rainfall patterns by months were essentially the same for all three periods as seen in Table 4. Capture and retention of snow by the standing stubble in the 1968-69 planting did little to increase seedling emergence under that treatment the following spring. No snow was captured by this treatment during the other two winters. Apparently soil moisture was not the prime limiting factor in affecting differences in seedling emergence among cultural treatments or among years.

Green needlegrass produced the highest number of seedlings in each of the three years, and exceeded the calibrated seeding rate of 10 PLS under the summer fallow treatment each year and the standing stubble treatment in 1968 (Tables 1,2 , and 3). This was due to the inherent embryo dormancy of the seeds, some of which is normally broken during the winter cold temperature period following planting.

The western and thickspike wheatgrasses and the switchgrass emergence in 1967 and 1968 was approximately half of the pure live seed planted. No explanation for the poor emergence in 1969 is available.

The performance of prairie sandreed was very poor under all cultural treatments and in all years. We thought that fall seeding of this warm-season grass caused a loss of seed viability and subsequent poor emergence, but other spring seedings and a
Table 5. Three-year average emergence of seedlings from five grasses seeded at a rate of 10 PLS per row foot across three cultural treatments. Seeded October 1966, 1967, and 1968; emergence recorded June 1967, 1968, and 1969, respectively. Averages of three replications.

\begin{tabular}{lrccc}
\hline & \multicolumn{3}{c}{ Cultural treatments } & \\
\cline { 2 - 4 } \multicolumn{1}{c}{ Grass species } & $\begin{array}{c}\text { Summor } \\
\text { fallow }\end{array}$ & $\begin{array}{c}\text { Tillcd } \\
\text { stubble }\end{array}$ & $\begin{array}{c}\text { Standing } \\
\text { stubble }\end{array}$ & Average \\
\hline Green needlegrass & 11.3 & 9.2 & 10.4 & $10.3 \mathrm{a}^{*}$ \\
Western wheatgrass & 5.0 & 3.3 & 3.4 & $3.9 \mathrm{~b}$ \\
Switchgrass & 3.9 & 3.1 & 4.1 & $3.7 \mathrm{~b}$ \\
Thickspike wheatgrass & 3.6 & 3.2 & 2.7 & $3.2 \mathrm{~b}$ \\
Prairie sandreed & 1.2 & 0.6 & 0.8 & $0.9 \mathrm{C}$ \\
Avcrage & 5.0 & 3.9 & 4.3 & 4.1 \\
& $\mathrm{x}$ & $\mathrm{y}$ & $\mathrm{xy}$ & \\
\hline
\end{tabular}

* Duncan's Multiple Range Test @ $\mathbf{P}=.01$, values with the same letters following are not significantly different.

variety of other soils and climates have shown the same poor emergence. ${ }^{2}$

The interaction of cultural treatments and species was not significant in 1967 but was highly significant $(\mathrm{P}=.01)$ in 1968 and 1969. Nevertheless, all species generally emerged better under the summer fallow treatment.

Summer fallow resulted in the greatest number of seedlings per row foot over the three-year period (Table 5). The treatment producing the least seedlings was tilled stubble. The additional moisture that might be expected to be available under the crop residue treatments did not provide better stands of grass over the summer fallow treatment. The tilled stubble was, in fact, a statistically distinct detriment. We did not determine if this detriment was due to a phytotoxicity of the crop residue, lower soil temperatures, shading, or some other factor.

For practical purposes of forage production and erosion control, on the other hand, all treatments achieved acceptable levels of seedling stands in this study. Stands of four to five plants per row foot, or seven to nine plants per square foot, were achieved with seeding rates one-third to one-half lower than those usually recommended for this type seeding. Since all interaction combinations of years, species, and cultural treatments were highly significant $(P=.01)$, a single approach to seeding grasses on dryland sites that will assure the greatest success appears impractical.

\section{Growth Suppression}

The fall 1967 seeding was allowed to grow through the seedling year (1968) and into the sec-

\footnotetext{
${ }^{2}$ Unpublished data, Soil Conservation Service, Plant Materials Center, Bridger, Montana.
} 


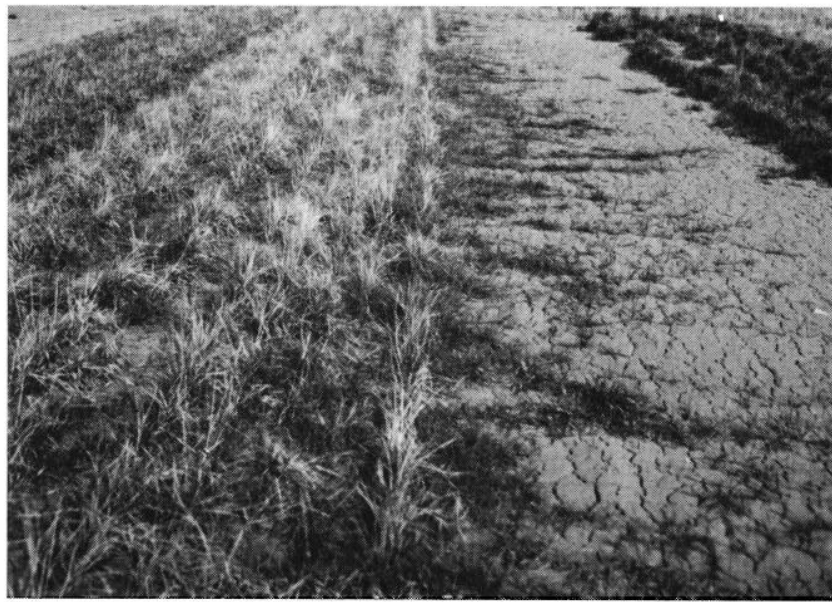

FIG. 1. Rhizomes from western wheatgrass plot on the left extending seven feet into empty plot on the right by April of the second growing season under summer fallow cultural treatment.

ond growing season (1969). A good stand of western wheatgrass was adjacent to a poor stand of prairie sandreed. During both the seedling and second growing seasons rhizomes of the western wheatgrass extended vigorously into the essentially empty area of the prairie sandreed. By the beginning of the second season these rhizomes had extended seven feet under the summer fallow treatment but only $1^{1 / 2}$ to 2 feet under the tilled stubble and standing stubble treatments (Figs. 1 and 2). Rhizome extension was measured from the center of the row adjacent to the empty area. This dramatic suppression of growth is attributed to the presence of the wheat straw residue. A deficiency of available nitrogen under the crop residue treatments may account in part for the poor rhizome spread, as well as the possibility of phytotoxicity from the residues.

Considerable evidence is available to show that many crop residues have a toxic effect on germination and growth of seedlings of crops that follow. The toxicity is caused partly by soil microorganisms which require certain plant residues as a substrate to elaborate toxic compounds (Behmer and McCalla, 1963; Norstadt and McCalla, 1968). Soluble substances in the plant residues can also cause poor seedling performance without the presence of microorganisms (Guenzi and McCalla, 1962; Guenzi et al., 1967; Behmer and McCalla, 1963). The most obvious phytotoxic symptoms are lower germination, loss of root geotropism, shortened first internode, stunting of the seedling, and general unthriftiness (Guenzi and McCalla, 1962; McCalla and Dudley, 1950; Norstadt and McCalla, 1968; Patrick and Koch, 1958; Behmer and McCalla, 1963). Phytotoxicity is most active during

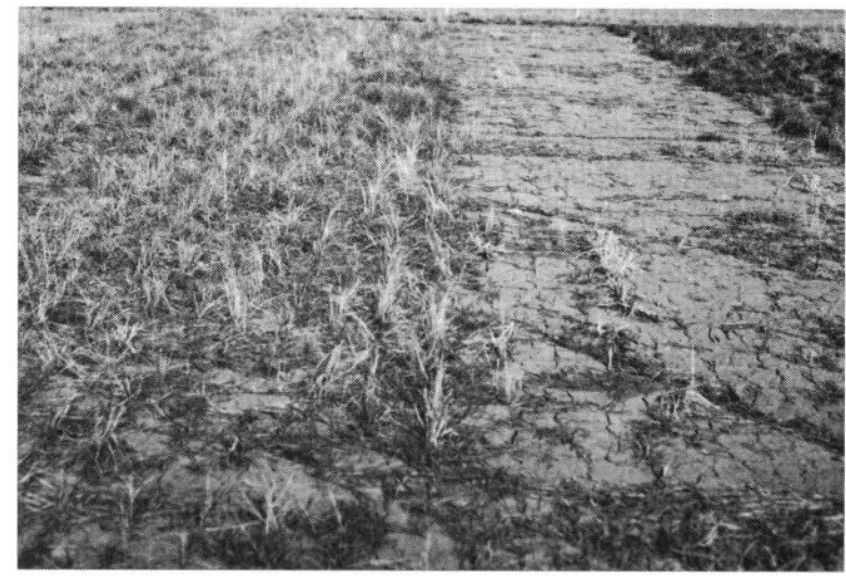

FIG. 2. Indistinct rhizome growth from western wheatgrass plot on the left extending two feet into empty plot on the right by April of the second growing season under standing stubble cultural treatment. Note that the stubble is almost non existent by the second season.

moist weather, or under the moist conditions promoted by the crop residue itself.

Growth suppression under crop residues was noted in one species in only one year of this study. No measurements were made on the four other species. We suggest further study of this phenomenon is needed.

\section{Summary and Conclusions}

The results of this investigation show that summer fallow culture will provide consistently better grass stands; but, for practical purposes, adequate grass stands can be established under any of the three cultural methods presently recommended; that a dramatic suppression of growth can occur under a crop residue culture; and that the particular soil, land condition, previous crop, moisture availability, and wind or water erosion hazard must be considered in the decision to use any one cultural treatment.

\section{Literature Cited}

Anderson, Darwin, Louis P. Hamilton, Hudson G. ReyNolds, And Robert R. Humphrey. 1957. Reseeding desert grassland ranges in southern Arizona. Ariz. Agr. Exp. Sta. Bull. 249.

Barnes, O. K., R. L. Lang, and A. A. Beetle. 1952. Grass establishment on Wyoming dryland. Wyo. Agr. Exp. Sta. Bull. 314.

Behmer, D. E., and T. M. McGalla. 1963. The inhibition of seedling growth by crop residues in soil inoculated with Penicillium urticae Bainer. Plant and Soil 18:199-206.

Clarke, S. E., and D. H. Heinrichs. 1941. Regrassing abandoned farms, submarginal cultivated lands, and depleted pastures in the prairie areas of western Canada. Canada Dep. Agr. FB. 103.

Douglas, Donald S., A. L. Hafenrighter, and K. H. Klages. 1960. Cultural methods and their relation to 
establishment of native and exotic grasses in range seedings. J. Range Manage. 13:53-57.

GuenzI, W. D., and T. M. McCalla. 1962. Inhibition of germination and seedling development by crop residues. Soil Sci. Soc. Amer. Proc. 26:456-458.

Guenzi, W. D., T. M. McCalla, and Fred A. Norstadt. 1967. Presences and persistence of phytotoxic substances in wheat, oat, corn, and sorghum residues. Agron. J. 59: 163-165.

Launchbaugh, J. L. (Ed.) 1966. A stand establishment survey of grass plantings in the Great Plains. Nebr. Agr. Exp. Sta. Great Plains Council Report No. 23.

McCalla, T. M., and F. L. Dudley. 1950. Stubble mulch studies. III Influence of soil microorganisms and crop residues on the germination, growth, and direction of root growth of corn seedlings. Soil Sci. Soc. Amer. Proc. 14: 196-199.
Norstadt, Fred A., and T. M. McCalla. 1968. Microbially induced phytotoxicity in stubble mulched soils. Soil Sci. Soc. Amer. Proc. 32:241-245.

Parker, Karl G. 1961. Seeding and using permanent pastures. Mont. State Univ. Ext. Bull. 312.

Patrick, Z. A., AND L. W. Koch. 1958. Inhibition of respiration, germination, and growth by substances arising during the decomposition of certain plant residues in the soil. Can. J. Bot. 36:621-647.

SitTler, Harry G. 1958. Economic possibilities of seeding wheatlands to grass in eastern Colorado. U.S. Dep. Agr. Bull. ARS 43-64.

Stark, R. H., J. L. Toevs, and A. L. Hafenrichter. 1946. Grasses and cultural methods for reseeding abandoned farm lands in southern Idaho. Idaho Univ. Agr. Exp. Sta. Bull. 267.

Staten, Hr W. 1943. Seeding native grasses. Okla. Agr. Exp. Sta. Circular C-108. 